\title{
GERENCIAMENTO DE OBRAS DA CONSTRUÇÃO CIVIL SOB A ÓTICA DO LEAN CONSTRUCTION: Aplicação em uma obra de urbanização
}

\author{
Johnnata Guilherme Gomes \\ Engenharia Civil pelo CEFET-RJ, Rio de Janeiro, RJ, Brasil \\ johnnata.gomes@gmail.com
}

Clézio Thadeu de Souza Dutra Doutor em sustentabilidade de obras pela Universidade Federal Fluminense (UFF) Professor do Departamento de Engenharia Civil CEFET-RJ, Rio de Janeiro, RJ, Brasil clezio@coneeng.com.br

Vinicius Araújo de Souza Dutra Mestrando em gestão em construção civil - Universidade Federal Fluminense (UFF) viniciusdutra@poli.ufrj.br

\section{RESUMO}

Diversos diagnósticos realizados no Brasil e no exterior indicam, que a maioria dos problemas que resultam em baixos patamares de eficiência e qualidade na construção civil, têm origem em problemas gerenciais. Nesse contexto, busca-se no setor da construção civil, novas filosofias para diferenciação estratégica e construtiva, que confiram ao projeto maior produtividade e liquidez, sendo uma delas, a construção enxuta - Lean Construction. A construção enxuta é uma filosofia de construção oriunda da produção enxuta - Lean Production, desenvolvida nas indústrias automobilísticas do Japão nos anos 50 , sendo o caso mais proeminente, o Sistema Toyota de produção. A construção enxuta introduz um novo paradigma para o processo de construção, em contraposição ao conceito usual de conversão, subdividindo o processo em atividades de conversão e de fluxo. Com isso, a identificação dos desperdícios se torna mais preciso e complexo, abandonando a ideia geral de que uma obra sem resíduos, constitui uma obra sem desperdícios. Uma vez que identificados os desperdícios, a construção enxuta atua como um antídoto, fornecendo bases teóricas que fomentará o processo de eliminação dos mesmos, e a melhoria continua da produção. A filosofia de construção enxuta é posta a prova no estudo de caso, de forma crítica e analítica, a fim de identificar a aplicabilidade dos conceitos em uma obra de construção civil, identificando conceitos e metodologias que mais apresentaram e não apresentaram impacto positivo. Ocorreu uma melhora significativa no andamento da obra, eliminando os desperdícios e trazendo maior rentabilidade para a empresa e, maior entrega de valor para o cliente.

Palavras-chave: Construção enxuta. Gerenciamento de processos. Produtividade.

\section{MANAGEMENT OF CIVIL CONSTRUCTION WORKS FROM THE PERSPECTIVE OF LEAN CONSTRUCTION: Application in an urbanization work}

\begin{abstract}
Several diagnoses carried out in Brazil and abroad indicate that most of the problems that result in low levels of efficiency and quality, in civil construction, originate from management problems. In this context, we are seeking in the construction sector, new philosophies for strategic and constructive differentiation, which will give the project greater productivity and liquidity, one of which is Lean Construction. Lean construction is a philosophy of Lean Production, developed in the
\end{abstract}


automobile industries of Japan in the 50 's, being the most prominent case, the Toyota Production System. Lean Construction introduces a new paradigm for the construction process, as opposed to the usual concept of conversion, subdividing the process into conversion and flow activities. The identification of waste becomes more precise and complex. Once the wastes are identified, the lean construction acts as an antidote, providing theoretical bases that will foster the process of elimination, and continuous improvement of production. The philosophy of lean construction is tested in the case study, in a critical and analytical way, in order to identify the applicability of the concepts in a construction work, identifying concepts and methodologies that presented the most and did not present a positive impact. Significant improvement in the progress of the work was noticed, eliminating waste and bringing greater profitability to the company, and greater delivery of value to the customer.

Key-words: Lean construction. Process management. Productivity.

\section{INTRODUÇÃO}

A indústria da construção civil (ICC) tem grande importância para a economia brasileira, visto que sua participação no Produto Interno Bruto - PIB é de 5,2\%, segundo à Câmara Brasileira da Indústria da Construção - CBIC (2018). Para Barros (2005), a relevância econômica da construção civil não se limita apenas à participação no PIB do país, mas também à sua expressão socioeconômica.

A construção civil é reconhecida pela sua grande capacidade de absorção de expressivos contingentes de mão de obra, incluindo profissionais menos qualificados e socialmente mais dependentes, mais suscetíveis a variabilidade econômica. Segundo o Portal Planalto (2016), Walter Cover, presidente da Associação Brasileira da Indústria de Materiais de Construção - ABRAMAT, relatou que a Indústria da Construção Civil empregava cerca de 13 milhões de pessoas em 2016, levando em consideração os empregos formais, informais e indiretos. Apesar da atual crise econômica do país, e o aumento no volume de demissões no setor, a construção civil continua sendo uma das maiores geradoras de emprego, principalmente para trabalhadores de baixa renda, o que é imprescindível para a retomada da economia brasileira.

Sua importância social vai além, pois é responsável pela produção da infraestrutura necessária para o desenvolvimento socioeconômico de uma nação, sejam elas: estradas, pontes, túneis, barragens, etc.

No ano de 2018, no cenário brasileiro, a indústria da construção civil atravessa um período de grandes desafios, como a crise econômica, política, retração de crédito e aumento da competição em um mercado desaquecido. Nesse contexto, no qual o mercado brasileiro insere-se, se faz 
necessária a busca pela diferenciação dos processos estratégicos e produtivos, com enfoque em práticas que visam à diminuição do desperdício sem que haja perda na qualidade final do produto.

O conceito da Lean Construction, conhecido no Brasil como Construção Enxuta, surgiu da adaptação do Lean Production, sistema criado pelas indústrias automobilísticas do Japão, e apresenta-se como forma de diferenciação do processo estratégico e competitivo das empresas do setor da construção civil, fornecendo melhores índices de produtividade com menores desperdícios e maior controle sobre os processos, o que concede maior liquidez para o projeto.

\section{SISTEMA TOYOTA DE PRODUÇÃO - STP}

O modelo Ford, criado por Henry Ford, implantou o sistema de produção em massa, através de linhas de montagem, incorporando conceitos pré-existentes de administração, com o objetivo da padronização dos produtos para uma montagem mais simples. Porém, ao mesmo tempo que este modelo era um sucesso na produção, Ford não conseguiu introduzi-lo com sucesso no âmbito gerencial. (LORENZON, 2008).

Em visitas a fábrica de produção da Ford (Indústria Automobilística Americana), a maior produtora automobilística da época, verificaram que os baixos custos para a produção em massa de poucos modelos, não era o sistema ideal para o mercado reduzido e demanda fragmentada do Japão, além de não entregar a qualidade exigida pelo mercado japonês. Também foram estimados nessa época, que a razão entre as forças de trabalho americanas e japonesas era de 1 para 9. (OHNO, 1997).

Com isso, era necessária a adaptação do processo de produção da Ford para o atual cenário do Japão, que segundo Ohno (1997), desenvolveu-se a partir de uma necessidade, pois certas restrições no mercado tornaram necessária a produção de pequenas quantidades de muitas variedades de produtos, sob condições de baixa procura; sendo este o destino da indústria automobilística japonesa no período de pós-guerra.

Toyoda e Ohno, listaram como as maiores dificuldades para a implantação do sistema Ford no Japão (LORENZON, 2008):

- Mercado doméstico limitado, o que demandava de um número maior de modelos de veículos;

- Força de trabalho não disposta a ser um custo variável;

- Falta de imigrantes temporários para trabalhar em situações precárias de trabalho, como acontecia nas empresas norte-americanas; 
- Concorrência no mercado interno com automobilísticas internacionais; e

- País devastado pela guerra.

Com esses dados, concluiu-se que seria necessário criar um novo sistema de produção, onde houvesse a eliminação do desperdício em termos de material, mão-de-obra e tempo, segundo Fugimoto (1999, apud LORENZON, 2008). E assim, foi criado na Toyota, indústria automobilística do Japão, o Sistema Toyota de Produção - STP.

O desperdício era o principal item a ser eliminado, e assim, o conceito de Just-in-time - JIT, tornou-se um dos pilares do STP. Este restringia o fornecimento de matéria prima, por parte da etapa anterior, apenas para suprir a necessidade imediata da etapa subsequente. (OHNO, 1997; WOMACK et al., 1992).

Este conceito era de difícil aceitação e implantação, pois a medida que fossem fornecidos apenas as quantidades necessárias à produção imediata, o estoque seria levado praticamente a zero, e qualquer falha no sistema produtivo poderia interromper completamente a produção. No entanto, Ohno (1997) enxergava essa característica como seu ponto forte, uma oportunidade de melhora, visto que todos os membros envolvidos se preocupariam em prever os problemas antes de se tornarem graves a ponto de parar a produção.

Com isso, Ohno instiga cada trabalhador da Toyota a se sentir parte integrante da equipe, e responsável pelo produto final. Para isto, se faz necessário que o mesmo tenha a ferramenta necessária para interferir e contribuir com o processo produtivo, surge assim, outro pilar do STP, o Jidoka. (WOMACK et al., 1992; SOUZA, 2010).

Ohno em administração à fábrica da Toyota implantou o conceito de Jidoka ao extremo, no início, relata Womack et al. (1992), que sua produção se interrompia constantemente e, com isso, sua produtividade despencava e seus custos se elevavam. No entanto, à medida que o tempo avançava e o sistema amadurecia, os erros foram se tornando cada vez mais raros, e a Toyota alcançava índices de produtividade e diminuição de produtos defeituosos nunca antes vistos. A Figura 1, mostra a Casa Toyota, uma representação do uso de suas filosofias.

Womack et al. (1992, p. 89) acrescenta:

A fábrica genuinamente enxuta possuí duas características organizacionais fundamentais: Transfere o máximo de tarefas e responsabilidades para os trabalhadores que realmente agregam valor ao carro, e possui um sistema de detecção de defeitos que rapidamente relaciona cada problema, uma vez descoberto, a sua derradeira causa. 


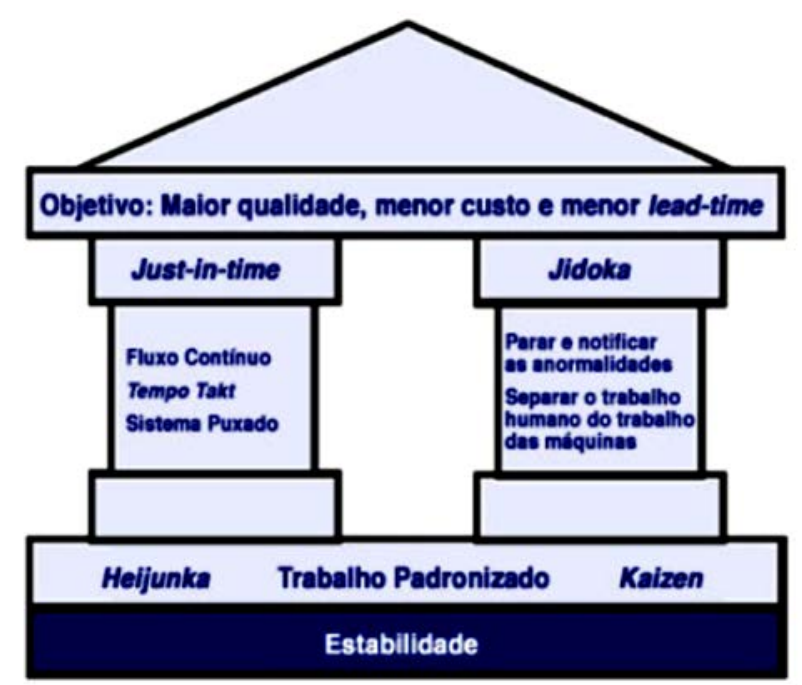

Fonte: (Lean Institute Brasil, 2018)

\subsection{Principais perdas no processo produtivo}

Existe na construção civil uma grande divergência quanto ao conceito de desperdício, bem como, de como medi-lo. Devido a isso, existem diversos estudos acerca dos indicadores de perdas. (ISATTO et al., 2000).

Ainda de acordo com Isatto et al. (2000), as perdas na construção civil, frequentemente, são tratadas como entulho, tais como madeira, blocos e outros materiais. No entanto, essa visão é simplificada e nem sempre correta, restringindo o potencial de melhoria efetivamente existente na empresa, induzindo a compreensão equivocada de que uma obra sem entulho é uma obra eficiente. Segundo Ohno (1997, p.71), "desperdício se refere a todos os elementos de produção que só aumentam os custos sem agregar valor - por exemplo, excesso de pessoas, de estoque e de equipamento". No entanto, para Isatto et al. (2000), uma parcela que não agrega valor pode ser considerada inerente ao processo a ser realizado, pois não haveria como erradicá-la sem a mudança no método de trabalho.

Ainda de acordo com Isatto et al. (2000), em análise ao movimento dos operários sugerida por Ohno (1997), o movimento do trabalho é dividido em trabalho e perda. O trabalho se divide em dois segmentos, como pode ser observado na Figura 2:

a. os que agregam valor; e

b. os que não agregam valor, mas são inerentes a realização do processo. Com isso, para Isatto et al. (2000), há uma parcela de perda aceitável (perda inevitável), que só poderia ser eliminado através de mudança significativa no desenvolvimento tecnológico e gerencial da empresa. Sendo assim, sugere a seguinte classificação para as perdas: 
a. Perdas inevitáveis (ou perda natural): Se refere à parcela de perda aceitável, onde o investimento necessário para a redução da mesma é inferior a economia gerada; e

b. Perdas evitáveis: É a parcela onde os custos para sua redução é inferior aos prejuízos gerados pela mesma. Decorre de processos ineficientes, no qual os recursos são empregados inadequadamente.

Figura 2 - Movimentos do trabalhador

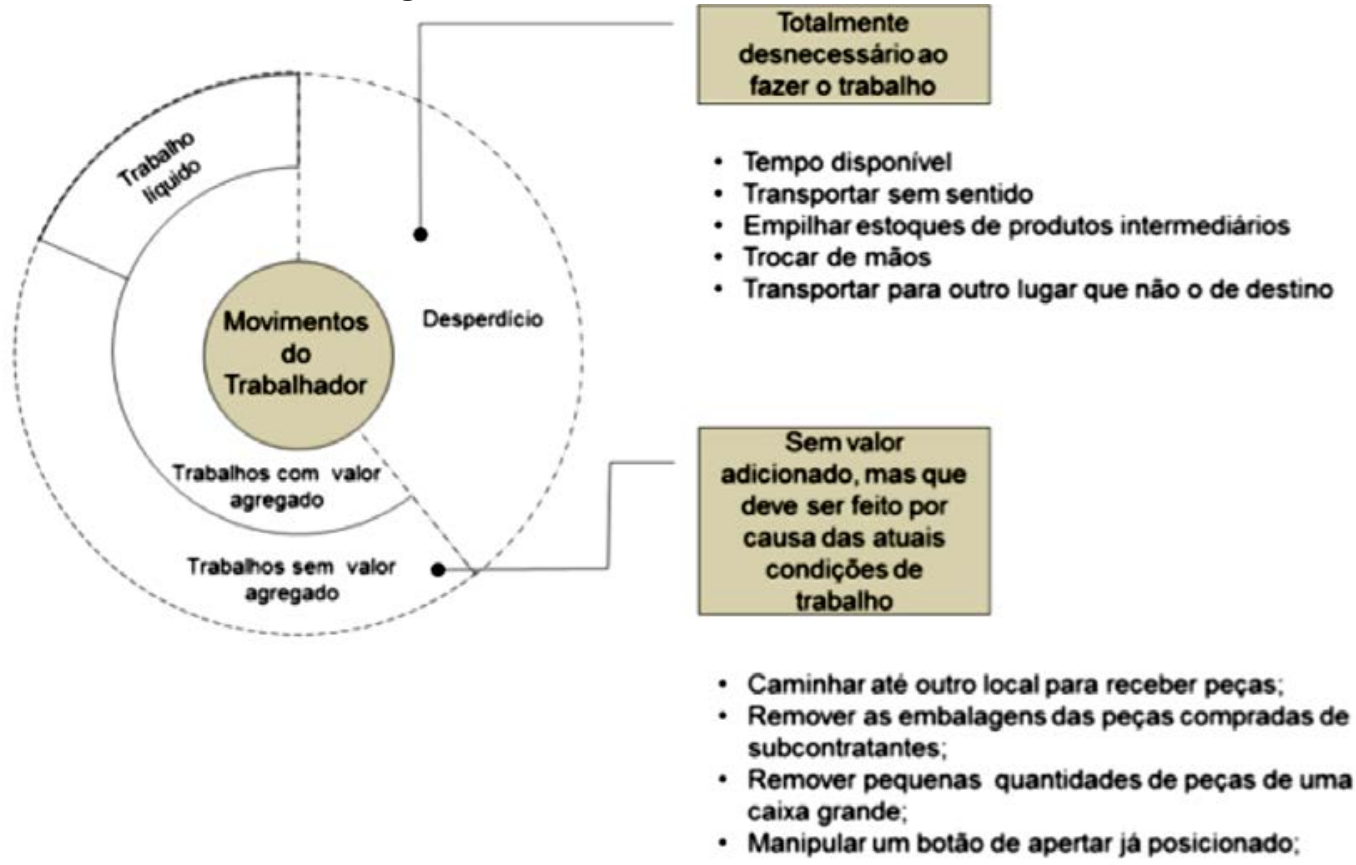

Fonte: Revista Espacios (2015, apud Ohno, 1997)

Ainda para Isatto (2000), a Figura 3 mostra os custos antes e depois de um processo de melhoria.

Figura 3 - Custos antes e após melhorias

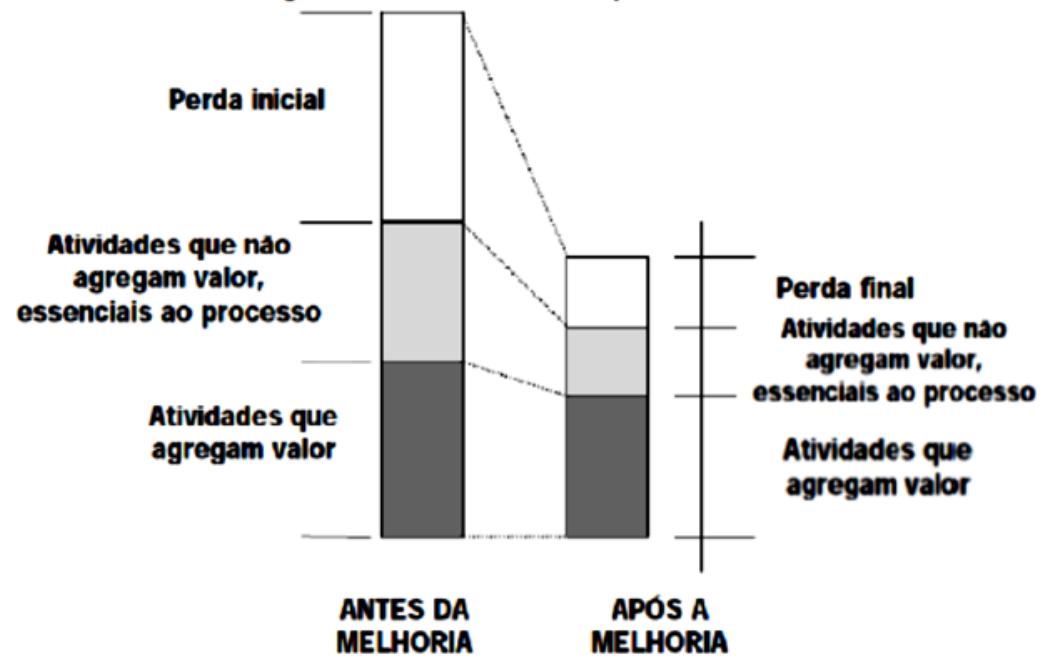

Fonte: ISATTO et al. (2000) 


\section{METODOLOGIA DO GERENCIAMENTO DE PROCESSOS}

A construção civil é identificada como um setor com elevada complexidade de processos, no Relatório do International Business Machines - IBM (1990, apud LIMA, 1998, p.36) define-se gerenciamento de projetos como:

Gerenciamento de processos consiste em uma metodologia que é utilizada para definir, analisar e melhorar continuamente o processo, objetivando atender as necessidades e expectativas do cliente em condições de excelência.

Varvakis (2000), afirma que todo processo possui características que nos fornecem informações para o acompanhamento e melhoria contínua do processo.

Tais como:

- Fluxo de valor: conjunto de passos que transformam insumos em produto ou serviço para o cliente;

- Eficácia: grau de realização da atividade planejada em atendimento à demanda do cliente;

- Eficiência: realização da tarefa consumindo o menor nível de recursos possíveis em atendimento à demanda do cliente;

- Tempo de ciclo: é o tempo necessário para execução de um processo do início ao fim; e

- Custo: esforço e trabalho despendido para execução de um processo.

Seguindo a metodologia de gerenciamentos dos processos do IBM (1990, apud PINTO, 1993), obtêm-se três grandes fases, subdivididas em diversas etapas:

Quadro 1 - 3 fases segundo o BIM

\begin{tabular}{|l|c|c|}
\hline \multicolumn{1}{|c|}{$\begin{array}{c}\text { Fase 1 - Definição do } \\
\text { Processo }\end{array}$} & Fase 2 - Análise do Processo & $\begin{array}{c}\text { Fase 3 - Melhoria do } \\
\text { Processo: }\end{array}$ \\
\hline Etapa 1: Organizar-se; & Etapa 5: Benchmarking; & Etapa 8: Teste e solução; e \\
Etapa 2: Caracterização dos & Etapa 6: Alternativas de & Etapa 9: Gerenciar \\
clientes; & soluções; & processos. \\
Etapa 3: Mapeamento dos & Etapa 7: Aprovação; & \\
processos críticos; & & \\
Etapa 4: Urgência; & & \\
\hline
\end{tabular}

Fonte: Os Autores

A Figura 4 contém o fluxograma que explica este método de gerenciamento, demonstrando as três fases explicitadas anteriormente, assim como suas respectivas etapas. 
Figura 4 - Método de melhoria contínua

MELHORIA CONTÍNUA

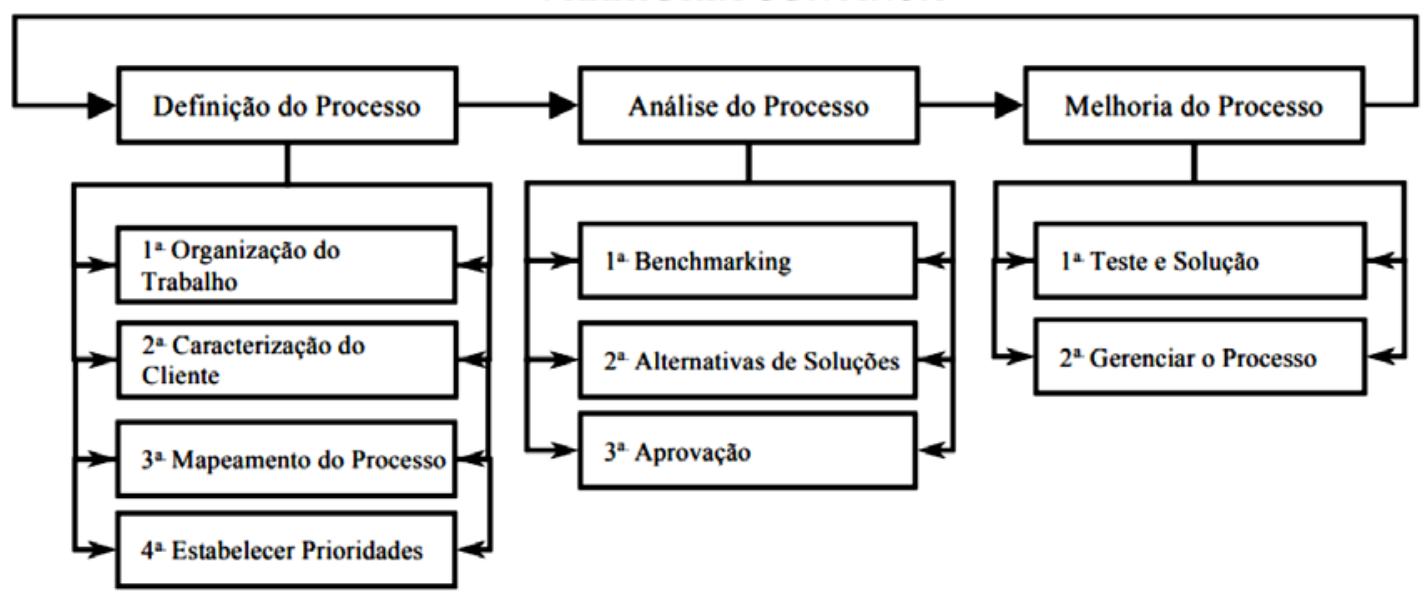

Fonte: IBM (1990, apud PINTO, 1993)

\section{CONSTRUÇÃO ENXUTA}

Segundo Isatto et al. (2000), o setor da construção civil, desde os anos 80, já vem se preocupando com os processos produtivos e qualidade do serviço, e para atender a essa nova necessidade, foi implementada a Gestão da Qualidade Total (Total Quality Management - TQM), pensando na eficiência dos processos. E assim, o segmento da construção voltou-se para o uso de gestão da qualidade e certificações, como a ISO 9001:2015. No entanto, segundo Formoso (2002), o sistema de gestão da qualidade não atendia por completo aos anseios do setor da construção civil, em não se aprofundar nos problemas recorrentes enfrentados no ramo.

Nos anos 90, insere-se um maior referencial teórico na aplicação da construção civil, principalmente no que tange as dificuldades relativas aos desperdícios inerentes aos processos construtivos. No entanto, havia ainda um conceito "enraizado" que desperdícios se constituíam, única e exclusivamente, de resíduos da construção civil.

De acordo com Isatto et al. (2000), devido a essa visão restrita dos desperdícios, as tentativas de reduzi-los não tiveram o êxito esperado. O sistema de gestão da construção enxuta foi concebido sob as premissas do STP, surgidos na década de 50 no Japão. Na década de 70 , foi posto à prova sob uma crise econômica, e se mostrou eficiente, obtendo resultados satisfatórios. Esse sistema de gestão tem por finalidade a diminuição de desperdícios da construção, com simplificações no fluxo de tarefas, com economia de custos e sem a perda da qualidade final do serviço. Essa filosofia é relativamente nova e ganhou maior notoriedade com a publicação do trabalho do professor finlandês Lauri Koskela em 1992, Application of the new production philosophy in the construction 
industry, publicado pelo CIFE - Center for Integrated Facility Engineering, ligado à Universidade de Stanford, EUA.

No qual o mesmo, posteriormente deu origem ao IGLC - International Group for Lean Construction, engajado na adaptação e disseminação do novo paradigma no setor da construção civil em diversos países.

\subsection{Dificuldades para implantação da construção enxuta}

Conforme Formoso (2002), Koskela fornece bases teóricas e desafia os profissionais do ramo da construção a analisarem e a adaptarem os procedimentos já perpetuados no STP.

Porém, a adaptação dos procedimentos do STP na construção civil apresenta dificuldades intrínsecas do ramo da construção civil, pois, em cada obra o objeto e, portanto, os próprios processos produtivos, se alteram. Logo, devemos pensar em uma obra da construção civil como um novo desafio para a implantação da gestão sobre a ótica da construção enxuta. (KOSKELA, 1992, tradução nossa; ISATTO et al., 2000).

A construção civil possui peculiaridades que a difere da indústria de fabricação. No entanto, segundo Koskela (1992, tradução nossa), essas diferenças não são impeditivas para a adoção de procedimentos bem estabelecidos e úteis na fabricação.

Warszawski (1990, apud KOSKELA, 1992, tradução nossa), cita as principais peculiaridades da construção civil:

- Natureza única dos projetos;

- Multi-organização temporária; e

- Intervenção regulatória.

\subsection{Paradigma enxuto}

$\mathrm{Na}$ construção civil o conceito de produção é definido pelo conjunto de atividades de conversão, que transforma insumos em produtos intermediários ou finais, e que estes podem ser subdivididos em subprocessos, que por sua vez, também são processos de conversão. No entanto, essa base teórica não considera a parcela de atividade de fluxos físicos entre as atividades de conversão que não agregam valor. (ISATTO et al., 2000).

Segundo Shingo (1996), a produção é formada por processos e operações, onde: 
- Processo: É o fluxo de materiais em relação ao tempo e ao espaço; a transformação dos materiais em produtos intermediários e finais; e

- Operações: É o trabalho para realizar esses processos.

Segundo Formoso (2002, p.3), "estima-se que cerca de dois terços (67\%) do tempo gasto pelos trabalhadores em um canteiro de obras estão nas operações que não agregam valor: transporte, espera por material, re-trabalhos, etc."

O novo paradigma do modelo "enxuto", no entanto, assume que os processos são constituídos de transporte, espera, processamento (ou conversão) e inspeção. As atividades de transporte, espera e inspeção não agregam valor para o cliente. (ISATTO et al., 2000).

Shingo (1996) apresenta uma breve definição desses elementos:

- Transporte: Movimento de materiais ou produtos, mudanças nas suas posições;

- Espera: Período no qual o material ou produto não sofre de qualquer processamento, inspeção ou transporte.

- Processamento: Mudança física no material ou mudança na sua qualidade (montagem ou desmontagem); e

- Inspeção: Comparação com um padrão estabelecido.

Para Shingo (1996), os processos podem ser melhorados de duas formas distintas. A primeira tem como princípio melhorar o produto em relação à engenharia de valor. A segunda é realizada em função da engenharia de produção ou tecnologia de produção.

Ainda de acordo com o mesmo autor (1996), o primeiro estágio para a melhoria do processo deve ser a engenharia de valor, onde se indaga sobre como produzir o produto com a mesma qualidade e menor custo de fabricação. Já no segundo estágio, deve ser melhorado o sistema produtivo em si, com melhores práticas e ferramentas tecnológicas.

É necessário salientar também, que todo subprocesso possui um custo específico, e a diminuição do mesmo fará com que o macroprocesso também diminua de custo.

Segundo Formoso (2002), na construção civil um processo se caracteriza por todas as etapas na transformação do insumo em serviços ao cliente, seja de forma direta, onde está diretamente relacionado com o produto final, bem como indireta, onde servirá de insumo para um próximo processo do ciclo de produção, como ilustrado na Figura 5. As atividades de transporte, espera e inspeção não agregam valor ao produto final, sendo por esta razão denominadas atividades de fluxo. 
Figura 5 - Modelo de processo na construção enxuta

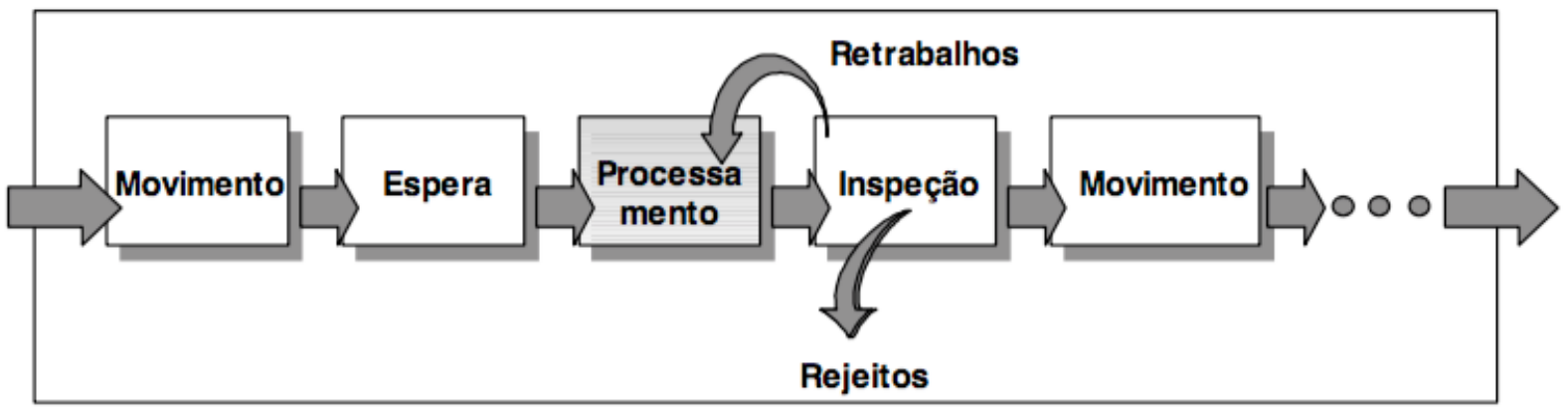

Fonte: Koskela (1992)

Entretanto, conforme Ohno (1997), não se deve aceitar passivamente o que está escrito no "manual", considerando que as circunstâncias são variáveis em cada caso, mas sim, entender porque deu certo, quais os princípios e técnicas pertinentes, e como eles poderiam servir para resolver a situação concreta em que o sistema produtivo está inserido.

A metodologia da construção enxuta é baseada nas premissas da metodologia da indústria automobilística japonesa, sendo seu caso mais proeminente: o STP, sendo adaptada para o canteiro de obras. Em seu trabalho Koskela (1992), estabelece onze princípios (BARROS, 2005), apresentados nos itens a seguir.

\subsubsection{Reduzir as atividades que não agregam valor}

Um dos fundamentos dessa metodologia é a redução da participação de atividades que não agregam valor, que são as atividades que dominam a maior parte dos processos.

\subsubsection{Consideração das necessidades dos clientes}

O valor é gerado através do cumprimento dos requisitos dos clientes internos ou externos, e não, como um mérito inerente da capacidade de produção.

No entanto, para Koskela (1992), os requisitos dos clientes não são considerados na filosofia de produção convencional.

\subsubsection{Reduzir a variabilidade}

Para Koskela (1992), processos de produção são variáveis, mesmo que para a produção de um mesmo produto, os recursos necessários para produzi-los (tempo, insumo, mão-de-obra) se alteram. 
Segundo Isatto et al. (2000), a variabilidade do processo de produção se divide em:

a. Variação dos processos anteriores, sejam eles externos (fornecedores) de material ou internos, etapa intermediária para a execução do processo;

b. Variação relativo a própria tarefa sendo executada; e

c. Mudança da demanda relativa ao cliente.

\subsubsection{Reduzir o tempo de ciclo}

Pode-se considerar tempo de ciclo como a soma de todos os tempos (transporte, espera, processamento e inspeção) para produzir um produto. Na construção civil onde os prazos para a execução são cada vez mais restritos, a compressão do tempo total de ciclo confere os seguintes benefícios para o processo (SCHMENNER, 1998; HOPP et al., 1990, apud KOSKELA, 1992):

a. Entrega mais rápida ao cliente;

b. Reduz a necessidade de fazer previsões sobre a demanda futura;

c. Diminuição da interrupção do processo de produção devido a pedidos de alteração; e

d. Gerenciamento mais fácil devido há menos pedidos de clientes para acompanhar.

\subsubsection{Simplificar através da redução do número de passos ou partes}

De acordo com Isatto et al. (2000), este método é frequentemente utilizado no desenvolvimento de sistemas construtivos racionalizados. As atividades que não agregam valor são proporcionais ao número de componentes ou passos de um processo, devido às etapas auxiliares de preparação e conclusão necessárias para cada passo no processo (por exemplo, montagem de andaimes, limpeza, etc.), e também pelo fato de que, em presença de variabilidade, tende a aumentar a possibilidade de interferências entre as equipes.

\subsubsection{Aumentar a flexibilidade de saída}

O aumento da flexibilidade ao processo como gerador de valor, embora esse princípio pareça contraditório à simplificação e aumento da eficiência, muitas empresas conseguiram realizar os dois objetivos simultaneamente. (STALK; HOUT, 1990 apud KOSKELA, 1992; ISATTO, 2000).

Segundo Stalk e Hout (1990) pode-se aumentar a flexibilidade mediante as seguintes abordagens: 
a. minimizar tamanhos de lote para corresponder de perto à demanda;

b. reduzindo a dificuldade de configuração e trocas;

c. personalizar o mais tarde possível no processo; e

d. formação de mão-de-obra polivalente.

\subsubsection{Aumentar a transparência do processo}

A falta de transparência além de propiciar a ocorrência de erros, reduz a visibilidade, dificultando a identificação dos mesmos, e ainda diminui a motivação para melhoria. Com isso, o objetivo se volta em tornar o processo transparente para aumentar o seu controle e melhoria contínua. (KOSKELA, 1992, tradução nossa).

Segundo Stalk e Hout (1990), deve-se tornar o processo de operações visível e compreensível para todos os integrantes da equipe. Esse objetivo pode ser conseguido através de medições e exibição pública de informações. Para Isatto et al.(2000), este princípio traz benefícios para o processo, pois aumenta o envolvimento da mão de obra no desenvolvimento de melhorias. Algumas abordagens práticas são citadas por Koskela (1992, tradução nossa) e Isatto et al. (2000): 1. Estabelecendo um programa de melhoria da organização e limpeza: o método do 5S;

2. Tornar o processo diretamente visível através de layout, com remoção de obstáculos visuais tais como divisórias e tapumes e sinalização apropriada;

3. Tornar atributos invisíveis do processo em visíveis através de medições, tais como nível de produtividade, número de peças rejeitadas, etc.; e

4. Utilizar controles visuais, tais como cartazes, sinalização luminosa e demarcação de áreas, para permitir que qualquer pessoa reconheça imediatamente informações relevantes para a gestão de produção.

\subsubsection{Focar o controle no processo global}

Esta etapa consiste em introduzir as melhorias no início dos processos para posteriormente analisar as melhorias nas operações. Segundo Isatto et al. (2000), um dos grandes riscos dos esforços de melhorias, é otimizar uma atividade específica dentro de um processo, sem levar em consideração os demais processos dependentes, resultando em um impacto reduzido, ou até mesmo negativo, no desempenho global do mesmo. 
Esta situação é muito comum em processos de produção fragmentados, como é a execução de uma obra, nos quais existem muitos projetistas, empresas subcontratadas e fornecedores independentes.

\subsubsection{Introduzir melhoria continua no processo}

O esforço para reduzir desperdícios e aumentar o valor é uma atividade interna e interativa, que pode e deve ser realizada continuamente. (KOSKELA, 1992). Para Isatto et al. (2000), este princípio é um componente fundamental de ambas as filosofias TQM e JIT.

Há várias medidas a serem implantadas para institucionalizar a melhoria contínua, o trabalho em equipe e a gestão participativa são requisitos essenciais, tais como:

a. Utilização de indicadores de desempenho para medir e monitorar melhorias;

b. Padronização de procedimentos, a fim de consolidar boas práticas e criar expertise na equipe para servir de referência para futuras melhorias;

c. Definir prioridades e metas a serem alcançadas; e

d. Vincular melhoria ao controle: a melhoria deve ser direcionada ao controle atual de restrições e problemas do processo. $\mathrm{O}$ objetivo é eliminar a raiz dos problemas em vez de implementações de ações corretivas.

\subsubsection{Equilíbrio entre melhorias nos fluxos e nas conversões}

Na melhoria de atividades produtivas, as atividades de conversão e de fluxos devem ser abordadas, sendo que estes possuem um potencial diferente de melhoria. As atividades de fluxo possuem maior melhoria em processos complexos, exigem menor investimento e são adequadas para início de programas de melhoria. As atividades de conversão, por sua vez, são mais adequadas onde há perda em relação à tecnologia de produção, sendo seus efeitos mais imediatos. (KOSKELA, 1992).

Ainda segundo Koskela (1992), as melhorias de fluxo e de conversão estão intimamente relacionadas, pois fluxos bem gerenciados propiciam a implantação de novas tecnologias, pois exigem menor capacidade de produção, não necessitando de altos investimentos em equipamentos para melhora do processo. Esses equipamentos por sua vez, aliados a fluxos bem planejados reduzem a variabilidade do produto, o que gera benefício para o processo. 


\subsubsection{Benchmarking}

Para Koskela (1992) e Pinto (1993), benchmarking consiste em um aprendizado de melhores práticas do mercado, objetivando a identificação de oportunidades de melhorias. Camp (1989, apud KOSKELA, 1992, tradução nossa) determina os seguintes passos para o benchmarking, apresentados na Figura 6.

- Planejamento - conhecer o processo;

- Coleta de dados - identificar os pontos fortes e fracos dos subprocessos;

- Análise;

- Adaptação; e

- Implementação.

Figura 6 - Etapas de Benchmarking

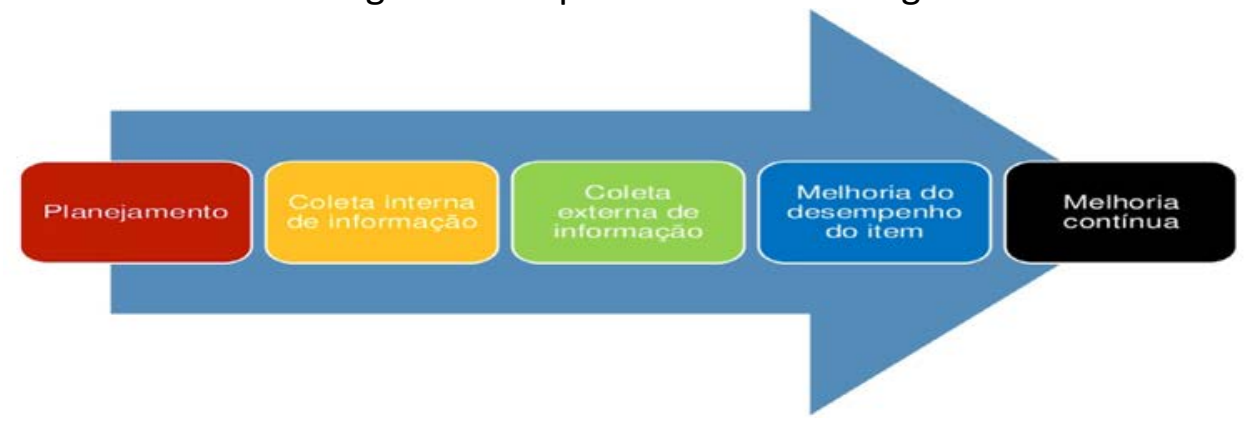

Fonte: FONTOURA et al. (s.d.)

\subsection{Ferramentas da construção enxuta}

\subsubsection{Kanbans}

Esta ferramenta consiste em quadros instalados no local de trabalho, para que se realize o controle da produção, através de informações sobre quando, quanto e o que produzir.

\subsubsection{Diagrama de Spaghetty}

De acordo com Côrtes (2014), esta ferramenta ajuda a determinar o layout ideal para que o fluxo de operários e movimentações ocorram de forma fluida, observando as distâncias percorridas para realização de cada atividade. 


\subsection{3 $5 \mathrm{~S}$}

Segundo Liker (2005), é uma metodologia criada no Japão que reúne um conjunto de atividades a fim de eliminar os desperdícios. Os 5S, apresentados na Figura 7, são:

- Seiri: Classificar os itens, mantendo o necessário e descartando o resto;

- Seiton: Organizar;

- Seiso: Limpar, procurar e corrigir imperfeições encontradas nas rotinas e equipamentos;

- Seiketsu: Padronizar, buscando manter os 3 primeiros S; e

- Shitsuke: Autodisciplina, atender aos 4 S sem necessidade de cobrança.

Figura 7 - Ferramenta dos $5 \mathrm{~S}$

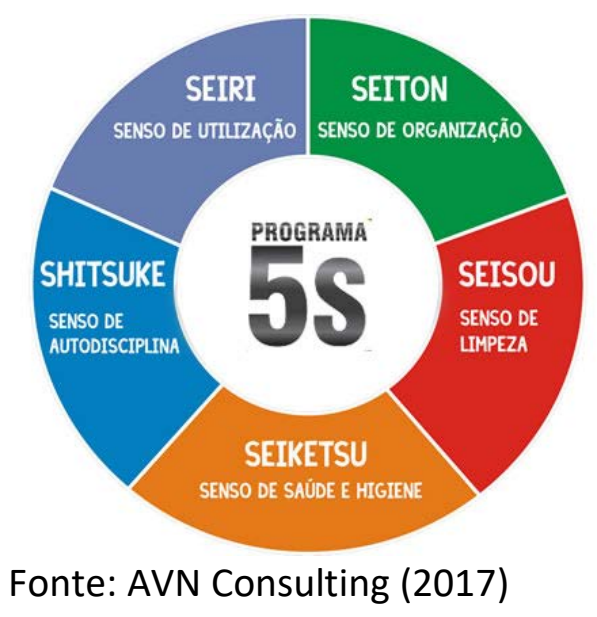

Segundo Campos (1992), a ferramenta 5S promove mudanças no comportamento da equipe de forma permanente, se perpetuando como filosofia de trabalho ordenado, para atingir ganhos de produtividade.

\subsubsection{Filosofia Kaizen}

Também de origem Japonesa, Kaizen significa "melhoria contínua". É uma ferramenta que visa criar processos que exijam o mínimo de estoque possível, para assim se tornar visíveis os possíveis desperdícios de tempo e recursos. Identificados os desperdícios, os funcionários utilizam o processo de melhoria contínua para extingui-los. (LIKER, 2005). 


\section{ESTUDO DE CASO}

O estudo de caso refere-se a uma obra pública licitada pelo município de Nova Iguaçu. A empresa contratada para execução da obra, é uma empresa familiar de pequeno porte, com sede na cidade de Paraty - RJ.

A obra possui caráter social, visto que o projeto tem como objetivo a construção de uma praça com quadra poliesportiva no bairro Ponto Chique, na cidade de Nova Iguaçu, tipicamente residencial.

Constituída de espaços para desenvolvimento das atividades físicas e de contemplação, a obra tem o objetivo de atender a população infantil, juvenil, adulta e da terceira idade, com quadra poliesportiva, academia da terceira idade, playground, pérgula e mesas de jogos.

\subsection{Hierarquia dos processos}

Antes de iniciar a análise de processos do estudo de caso, faz-se necessária, como requisito inicial, a sua identificação com o máximo de detalhamento possível. Eventualmente, uma análise mais profunda do orçamento do projeto, revela informações valiosas, à medida que uma análise mais simplificada e superficial, pode conduzir a uma avaliação de menor importância.

A Figura 8 mostra a participação financeira de cada processo da obra.

Figura 8 - Participação financeira dos processos antes da análise

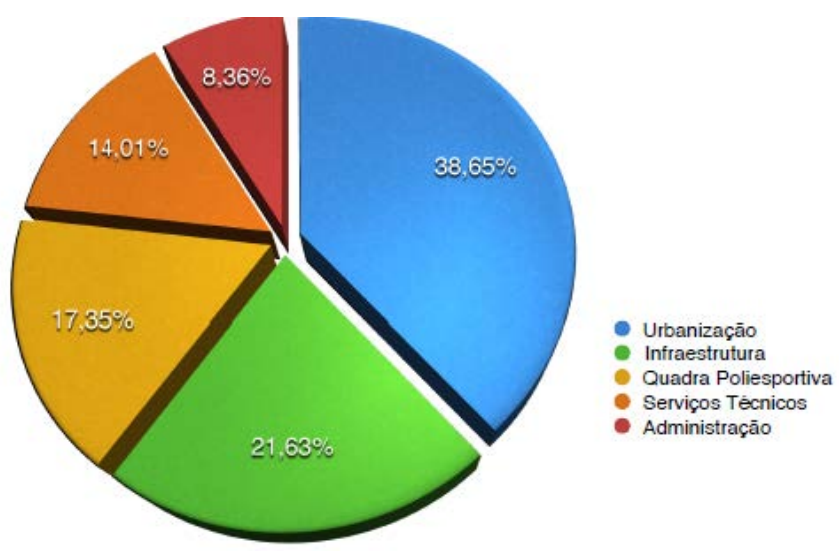

Fonte: Os Autores (2018)

Informações essas, extraídas do orçamento da mesma, conforme Anexo A, sem qualquer nível de detalhamento mais acurado. 
No entanto, torna-se necessária a hierarquização dos processos com maior nível de detalhamento, agrupando-os em macroprocessos, processos e subprocessos, pois, a comparação de um macroprocesso com um processo ou um subprocesso, conduz a uma análise ineficaz.

As Figuras 9, 10 e 11 fornecem um maior detalhamento dos processos e uma divisão mais coerente do estudo de caso.

Figura 9 - Detalhamento dos processos

\begin{tabular}{|c|c|c|}
\hline $\begin{array}{l}\text { Serviços } \\
\text { Técnicos }\end{array}$ & Urbanização & $\begin{array}{l}\text { Quadra } \\
\text { Poliesportiva }\end{array}$ \\
\hline - Serviços Iniciais & - Urbanização / Paisagismo & - Serviços Complementares \\
\hline - Movimento de Terra & \multirow{2}{*}{$\begin{array}{l}\text { - Aparelhos Elétricos, Hidráulicos, } \\
\text { Sanitários, Esportivos }\end{array}$} & - Estrutura \\
\hline \multirow{2}{*}{ - Transporte } & & - Revestimento \\
\hline & - Estrutura & - Esquadria \\
\hline Infraestrutura & & $\begin{array}{l}\text { - Instalações Elétricas, Hidráulicas, } \\
\text { Sanitárias e Esportivas }\end{array}$ \\
\hline - Serviços Preliminares & & \multirow{2}{*}{$\begin{array}{l}\text { - Aparelhos Elétricos, Hidráulicos, } \\
\text { Sanitários e Esportivos }\end{array}$} \\
\hline \multicolumn{2}{|c|}{ - Galerias Drenos e Conecções } & \\
\hline - Iluminação de Praça & & - Pintura \\
\hline
\end{tabular}

Fonte: Os Autores (2018)

Figura 10 - Hierarquização dos processos: Urbanização

\section{Urbanização} Macroprocesso
Subprocessos

- Urbanização / Paisagismo

- Aparelhos Elétricos, Hidráulicos, Sanitários, Esportivos

\section{Macroprocesso}

- Estrutura

Fonte: Os Autores (2018)

\section{Processos}

Área de Lazer (Praça)

Muro de Pedra Argamassada

Escada 
Figura 11 - Hierarquização dos processos: Quadra Poliesportiva

\section{Subprocesso}

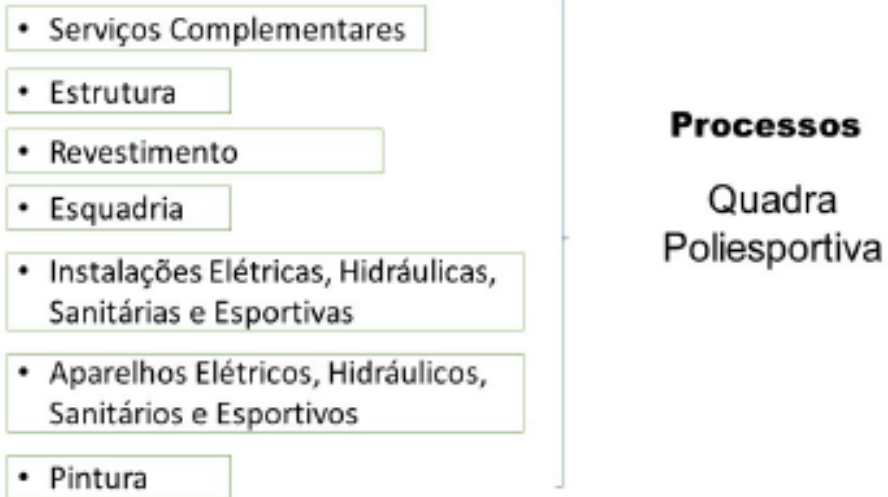

Fonte: Os Autores (2018)

É possível verificar na Figura 16, que a urbanização é na verdade, um macroprocesso, que por sua vez, é composto de outro macroprocesso e dois subprocessos, que analisados com mais acuidade, se referem a construção de três objetos, sendo eles: praça, muro de pedra argamassada e escada.

Observou-se que a quadra poliesportiva é o objeto a ser construído, sendo assim, considerado o processo a ser analisado. Todos os demais itens são considerados subprocessos, pois referem-se a etapas necessárias para que o processo, quadra poliesportiva, seja realizado.

Após realizada a interrelação dos processos, concluiu-se que havia necessidade de reavaliar os percentuais correspondentes a cada processo identificado.

A Figura 12 mostra o novo percentual de participação financeira dos processos, muro de pedra argamassada, praça, quadra poliesportiva e escada, em relação ao preço global da obra. Dados estes extraídos dos Apêndices A e B.

Figura 12 - Participação financeira após da hierarquização dos processos

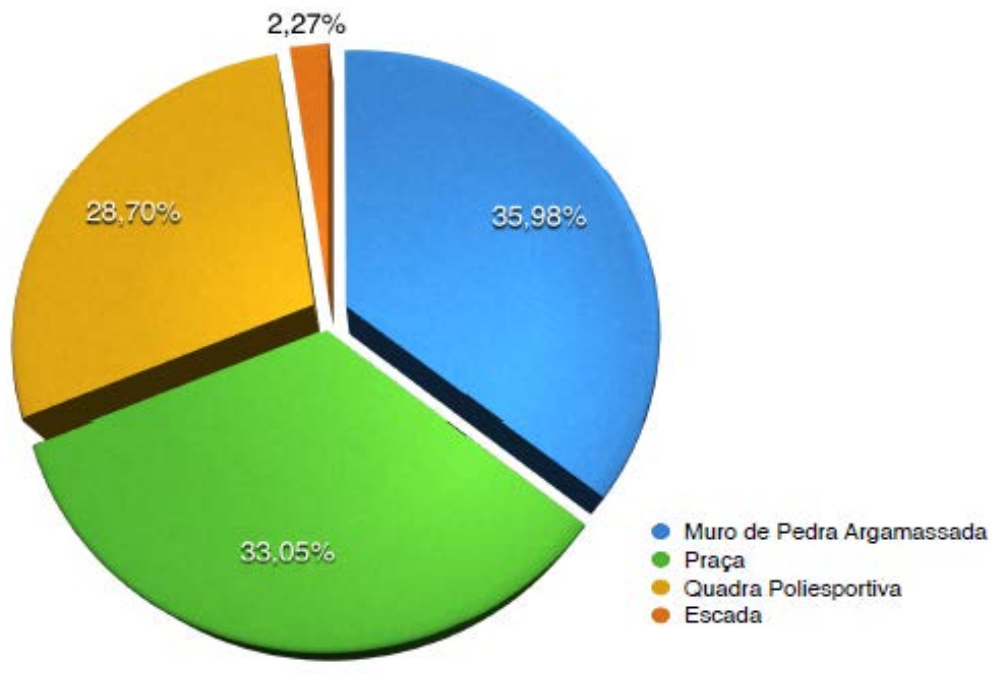

Fonte: Os Autores (2018) 
Foi possível concluir os processos mais relevantes financeiramente, sendo eles: muro de pedra argamassada, praça, quadra poliesportiva e escada respectivamente. O que difere do resultado obtido anteriormente, que apenas ilustrava os dados presentes no orçamento.

Verificou-se que o não detalhamento dos macroprocessos e da sua hierarquização, iria ocultar processos de maior relevância financeira, mesmo que em macroprocessos de menor relevância.

\subsubsection{Escolha do processo crítico}

Para a realização do estudo de caso foi selecionado o processo onde, pela percepção da equipe, iria provocar maior mudança e agregar maior valor para o cliente. Para isto, analisou-se cada processo de maneira analítica sobre os seguintes parâmetros:

1. Maior importância para o cliente;

2. Maior impacto financeiro na obra;

3. Importância para segurança e

4. Crítico para outros setores.

As Tabelas 1 e 2, sintetizam os processos escolhidos para a avaliação, mostrando seu grau de importância atribuído pela equipe e a gravidade de cada critério, respectivamente.

Tabela 1 - Critérios de avaliação

\begin{tabular}{ll|c}
\multicolumn{1}{c|}{ CRITÉRIOS } & \multirow{2}{*}{$\begin{array}{c}\text { GRAU DE } \\
\text { IMPORTÂNCIA } \\
\%\end{array}$} \\
\cline { 1 - 2 } AGREGA MAIOR VALOR PARA O CLIENTE & AV & 30 \\
\cline { 1 - 2 } MAIOR IMPACTO FINANCEIRO NA OBRA & IF & 25 \\
\cline { 1 - 2 } INSALUBRIDADE & IS & 10 \\
\cline { 1 - 2 } CRÍTICO PARA OUTROS SETORES & CS & 20 \\
\cline { 1 - 2 } COMPLEXIDADE DO PROCESSO & CP & 15 \\
\hline
\end{tabular}

Fonte: Adaptado Pinto (1993)

Tabela 2 - Peso para gravidade do critério

\begin{tabular}{l|c}
\hline GRAVIDADE DO CRITÉRIO & PESO \\
\hline MUITO PEQUENA & 1 \\
PEQUENA & 2 \\
MÉDIO & 3 \\
GRANDE & 4 \\
MUITO GRANDE & 5 \\
\hline
\end{tabular}

Fonte: adaptado Pinto (1993) 
Com a escala de pontuações determinadas foi possível criar uma matriz de decisão para a escolha do processo a ser analisado. Em seguida é feito uma breve explicação do peso atribuído para cada critério do processo selecionado, conforme Tabela 3.

\begin{tabular}{|c|c|c|c|c|c|c|c|c|}
\hline & & \multicolumn{5}{|c|}{ CRITÉRIOS } & \multirow{3}{*}{$\boldsymbol{\Sigma}$} & \multirow{3}{*}{$\%$} \\
\hline \multirow{2}{*}{\multicolumn{2}{|c|}{$\begin{array}{l}\text { GRAU DE IMPORTÂNCIA DOS } \\
\text { CRITÉRIOS }\end{array}$}} & AV & IF & IS & cs & CP & & \\
\hline & & 30 & 25 & 10 & 20 & 15 & & \\
\hline $\mathbf{P}$ & $\begin{array}{l}\text { URBANIZAÇÃO E } \\
\text { PAISAGISMO }\end{array}$ & 5 & 3 & 2 & 1 & 3 & 3,1 & 20,06 \\
\hline $\mathbf{R}$ & MURO DE ARRIMO & 4 & 5 & 5 & 5 & 5 & 4,7 & 30,42 \\
\hline c & QUADRA POLIESPORTIVA & 5 & 4 & 3 & 2 & 4 & 3,8 & 24,60 \\
\hline $\begin{array}{l}\mathbf{E} \\
\mathbf{S}\end{array}$ & $\begin{array}{l}\text { GALERIA, DRENOS E } \\
\text { CONECÇÖES }\end{array}$ & 4 & 3 & 3 & 5 & 4 & 3,85 & 24,92 \\
\hline $\begin{array}{l}\mathbf{S} \\
\mathbf{0}\end{array}$ & TOTAL & & & & & & 15,45 & 100 \\
\hline
\end{tabular}

Fonte: Adaptado de PINTO (1993)

Com base na pontuação obtida na matriz de tomada de decisões, o processo de construção do muro de arrimo de pedra argamassada com base de concreto ciclópico foi escolhido para um estudo mais aprofundado. Para tornar claro a importância desse processo para a obra, foi realizada uma explicação sucinta sobre a pontuação atribuída para cada item.

\section{CONCLUSÃO}

O trabalho apresentado evidencia as dificuldades de gerenciamento encontrados na construção civil, por ser uma atividade que possui características únicas diferentes de outras indústrias. No entanto, verifica-se que novas filosofias estão emergindo para a melhoria contínua do processo de construção.

Observou-se que para a melhoria do processo de construção, o setor da construção civil necessita abandonar os velhos paradigmas "enraizados" para adoção das novas filosofias com melhores práticas de gerenciamento de processos, entre estas a filosofia de construção enxuta. A filosofia de construção enxuta, apresenta-se como ferramenta eficaz para nortear o controle e gerenciamento dos processos construtivos da construção civil, diminuindo desperdícios e trazendo à luz oportunidades de ganhos antes não explorados. 
No estudo de caso, viu-se que, apesar de uma equipe bem alinhada e em constante processo de controle da obra por parte da gerência, ocorreram alguns desperdícios na produção. Esses erros, sob a ótica da construção enxuta, foram identificados e solucionados utilizando ferramentas dessa metodologia. Com isso, notou-se uma melhora significativa no andamento da obra, eliminando os desperdícios e trazendo maior rentabilidade para a empresa e, maior entrega de valor para o cliente.

\section{REFERÊNCIAS}

ASSOCIAÇÃO BRASILEIRA DE NORAS TÉCNICAS - ABNT. NBR ISSO 9001:2015. Disponível em: https://www.abntcatalogo.com.br/norma.aspx?ID=345041. Acesso em: Novembro de 2018.

AVN Consulting. $5 \mathrm{~S}$ ferramenta eficaz para melhorar o desempenho e qualidade. Disponível em: https://avnconsulting.com.br/cursos-treinamentos/5-s-ferramenta-eficaz-para-melhorar-odesempenho-e-qualidade/. Acesso em: Abril de 2018.

BARROS, E. S. Aplicação da Lean Construction no setor de edificações: um estudo multicaso. 2005. 126f. Dissertação (Mestrado em Engenharia de Produção). Programa de Pós-Graduação em Engenharia de Produção. Recife: Universidade Federal de Pernambuco, 2005.

CÂMARA BRASILEIRA DA INDÚSTRIA DA CONSTRUÇÃO - CBIC. Apostila excelência em gestão na construção. Brasília: 2017. Disponível em:

<https://cbic.org.br/Excelencia_em_Gestao_na_Construcao_2017.pdf> Acesso em: 15 de Abril de 2018.

CÔRTES, Alexandre Morgani de Menezes. Impactos da metodologia Lean Production em obras de Engenharia. Rio de Janeiro: UFRJ/ Escola Politécnica, 2014.

FONTOURA, P. et al.REENGENHARIA DE PROCESSOS BENCHMARKING. Disponível em: https://pt.slideshare.net/fontoura60/reengenharia-de-processos-benchmarking Acesso em: Abril 2018.

FORMOSO, Carlos T. Leal Construction: Princípios Básicos e exemplos. Escola de Engenharia. Rio Grande do Sul: UFRGS, 2002.

INTERNATIONAL BUSSINES MACHINES - IBM BRASIL. Enfoque de Qualidade no Processo de Negócio. Rio de Janeiro, 1990.

ISATTO, et.al. Lean construction: diretrizes e ferramentas para o controle de perdas na: Construção Civil. Porto Alegre: SEBRAE/RS, 2000.

KOSKELA, L. Application of the New Production Philosophy to Construction. Technical Report, 72. Stanford: Stanford University, 1992.

LEAN INSTITUTE BRASIL. Disponível em: https://www.lean.org.br/. Aceso em Abril de 2018. 
LIKER, Jeffrey K. O Modelo Toyota: 14 Princípios de Gestão do Maior Fabricante do Mundo. Porto Alegre: Editora Bookman, 2005.

LIMA, Adalberto da C. Gerenciamento de Processos na Execução do Macroprocesso Construtivo: um estudo de caso aplicado no processo estrutural. 186f. Dissertação (Mestrado em Engenharia de Produção). Curso de Pós-Graduação em Engenharia de Produção e Sistemas, Universidade Federal de Santa Catarina, 1998.

LORENZON, I. A. A Medição de Desempenho na Construção Enxuta: estudos de caso. 219 f. Tese (Doutorado em Engenharia Civil). São Carlos: UFSC, 2008.

OHNO, T. O Sistema Toyota de Produção. Porto Alegre: Editora Artes Médicas Sul Ltda, 1997.

PINTO, Jane Lúcia G. C. Gerenciamento de Processos na indústria de móveis. Dissertação. Departamento de pós-graduação em engenharia de produção e sistemas. Florianópolis: UFSC, 1993.

PORTAL PLANALTO. Construção civil emprega 13 milhões de pessoas no País. Brasília: 2016. Disponível em: http://www2.planalto.gov.br/acompanheplanalto/noticias/2016/08/construcaocivil-emprega-13-milhoes-de-pessoas-nopais Acesso em: 3 de Abril de 2018.

SHINGO. O Sistema Toyota de Produção do ponto de vista da engenharia de produção. Trad. por: Eduardo Schaan. 2 Ed. 291p. Porto Alegre: Artes Médicas, 1996.

SOUZA, M. R. Considerações sobre a implementação de princípios de construção enxuta em construtoras de médio porte. Universidade Federal de Minas Gerais -UFMG. Departamento de Engenharia de Materiais e Construção. UFMG: Belo Horizonte, 2010.

STALK, G.; HOUT, T.M. Competindo contra o tempo: como a competição baseada no tempo está remodelando o março global. Editora Simon e Schuter, 1990.

VARVAKIS, G. J. R. et. al. Gerenciamento de processos. 71p. Apostilha de disciplina (Gerenciamento de processos \& variável ambiental). Programa de Pós - Graduação em Engenharia de Produção e Sistemas. Santa Catarina: UFSC, 2000.

WOMACK, J. et al. Lean Thinking: Banish Waste and Create Wealth in Your Corporation. Nova York: Simon \& Schuster, 1996.

WOMACK, J. P.; JONES, D. T.; ROSS, D. A máquina que mudou o mundo. Tradução de Ivo Korytowski. Rio de Janeiro: Campus, 1992. 